\title{
EXPLORANDO E DESVENDANDO REGRAS DA PERCEPÇÃO
}

\author{
Suzete Venturelli ${ }^{1}$
}

\section{Resumo}

Para as ciências humanas a arte é uma categoria especial de atividade humana. Por exemplo, discute-se perspectivas diferentes sobre o que faz com que um objeto seja ou não arte? Alguns pontos de vista filosóficos descrevem a arte como "imitação" (Platão), "redenção" (Nietzsche), ou "comunicação de sentimento" (Tolstoi); há mais visões recentes de arte como "fetiche" (Adrian Piper), "virtual" (Douglas Davis) ou computacional, no nosso caso. A arte também é definida do ponto de vista dos espectadores, ou seja, a arte é aquilo que é categorizado pelos espectadores como tal. Este texto visa refletir um ponto de vista específico que relaciona a arte, estética e alguns aspectos da psicobiologia que fundamentaram a teoria de um trabalho artístico intitulado Tijolo Esperto.

Palavras-chave: Arte Computacional, Psicobiologia, Neuroestética.

\begin{abstract}
Art is a special category of human activity for the human scientists. For example, we discuss what makes an object is art or not? Some philosophical viewpoints describe art as a virtual "imitation" (Plato the philosopher) "Redemption" (Nietzsche the philosopher), or "communication of feeling" (Tolstoy), are newer visions of art as "fetish" (Adrian Piper) "'"(Douglas Davis) or computer in our case. The art is also defined from the point of view of spectators, ie the art is that which is categorized as such by viewers. This text aims to reflect a particular viewpoint that relates to art, aesthetics and some aspects of the psychobiology that underlie the theory of an artwork titled Smart Brick.
\end{abstract}

Keywords: Computer Art, Psychobiology, Neuroaesthetic.

\footnotetext{
${ }^{1}$ Professora da Universidade de Brasília, Instituto de Artes/Departamento de Artes Visuais. Pesquisadora do CNPq. Artista e escritora.
} 
O que a neurociência tenta comprovar hoje, filósofos já vinham desvendado pela imaginação. O filósofo David Hume, por exemplo, argumentava que a beleza está em quem vê, e não no objeto. Para Gilles Deleuze, pós-estruturalista, isso reflete uma crítica aguda da representação na arte, rumo ao conhecimento pelo instinto. Segundo Gilles Deleuze:

\begin{abstract}
"Hume não faz uma crítica das relações, mas uma crítica das representações, justamente porque estas não podem apresentar as relações. Fazendo da representação um critério, colocando a ideia na razão, o racionalismo colocou na ideia aquilo que não se deixa constituir no primeiro sentido da experiência, aquilo que não se deixa dar sem contradição numa ideia, a generalidade da própria ideia e a existência do objeto, o conteúdo das palavras [...]. Nesse sentido, a razão será chamada instinto, hábito, natureza" (DELEUZE: 2001, p. 22).
\end{abstract}

O filósofo Hume compara a imaginação a uma coleção de percepções e faz ver que ela opera mediante princípios de associação, onde o espírito ocorre a partir das percepções, se originando na relação que define, e não pode ser compreendido como algo que torna possíveis as percepções. O filósofo diz que o espírito é um feixe de percepções e não mais uma condição para as percepções, por isso o destaque de Deleuze em mostrar que o espírito (cérebro?) é idêntico à ideia de algo.

Gilles Deleuze (2007), por sua vez, em Imagem-Movimento e a Imagem-Tempo nos convida a sentir junto com ele a intensidade das percepções na filosofia do acontecimento da multiplicidade, que rompem com a filosofia do sujeito passivo, na distinção entre o sujeito e aquilo que lhe é mostrado. Parte do pressuposto que a empatia artística (beleza?), assim como Hume, está em quem vê e não no objeto. A questão da percepção que estuda, sobretudo no cinema, levaram-no a sugerir que na prática da visualização cinematográfica, principalmente no Cinema Moderno. No cinema cerebral moderno, como ele denomina, não ocorre o encadeamento de imagens associadas e sim o re-encadeamentos de imagens independentes que apresentam uma relação aditiva ("e"): “ ...há uma imagem mais outra, e cada plano é desenquadrado em relação ao enquadramento do plano seguinte" (DELEUZE, 2007, p. 255). Ocorre assim a não distinção do objeto e do sujeito (objetivo e subjetivo; real e imaginário; atual e virtual) que a imagem do pensamento se formula, ou melhor, o impensado do pensamento. Atualmente, os resultados das experiências em Neurocinemática indicaram um controle mental de determinados filmes, ou seja, de sua estética sobre o espectador, pois a estética dos filmes provocam certas reações que ajudam a entender o funcionamento do cérebro. Desenvolveram, então, método para analisar o funcionamento cerebral do espectador diante da tela.

Por exemplo, no contexto de experiências estéticas realizadas por Daniel Berlyne 
(1970), professor de psicologia da universidade de Toronto, ele buscou entender os fatores que levam certos indivíduos a se motivarem para produzir arte, assim como, passou a se interessar por questões sobre os estímulos visuais. Estudando as respostas fisiológicas, como o aumento da frequência cardíaca,e de hormônios percebidos por meio de estímulos visuais, verificou que o novo, o complexo e a ambiguidade provocavam um estado de alerta que influenciava diretamente nas respostas emitidas, bem como no prazer que os estímulos insinuavam. A experiência consistia em mostrar figuras com diferentes graus de complexidade, variando o tempo e a repetição de exposição das mesmas.

As figuras eram classificadas como muito agradáveis até muito desagradáveis, em diferentes momentos da experiência. As experiências mostram que figuras simples e estímulos monótonos praticamente não interessavam e eram menos prazerosos a cada apresentação. Já os estímulos novos e os complexos estimulavam, e se tal estímulo fosse moderado as figuras eram consideradas agradáveis, mas se fosse muito intenso, ocorria o desprazer. No entanto, com a apresentação repetida das figuras complexas, a novidade reduzia-se lentamente, não a ponto de tornar a experiência tediosa, mas suficiente para reduzir a intensidade do alerta gerado, tornando a experiência agradável.

O artista Maurits Cornelis Escher certamente conhecia este recurso por outros caminhos, afirma o cientista. Suas gravuras e desenhos levam a uma sensação de estranhamento inicial que a cada nova exposição diminui um pouco. No entanto, como possuem algo de impossível, paradoxo, provoca tensão suficiente para estimular o alerta, dando à experiência estética um sabor constante de novidade. Ao falar sobre suas criações, Escher mostrou que, mesmo não sendo psicólogo, conhecia perfeitamente esse processo, pois sabia que havia certo enigma nelas, mas que não era captado imediatamente pelo olhar. Enigma provocado pelo mundo do paradoxo que ilustra a construção do impossível, tão presente nas suas imagens.

No contexto das experiências estéticas, apresento como exemplo, um trabalho que coordenamos no Midialab, no contexto de Iniciação Científica, intitulado Tijolo Esperto. Para uma melhor visualização do processo de trabalho que culminou na instalação foi importante dividir o sistema interativo tangível em três instâncias: o input, o processamento e o output. 1) O input consiste na obtenção de informações através de sensores capazes de fornecer informações passíveis de serem computadas. 2) O processamento interpreta a informação obtida de acordo com as relações implementadas através da programação. 3) O output é a 
expressão física na qual é expressado o resultado das informações computadas. De certo modo, repetimos aqui a experiência de Berlyne, comentada, onde observamos as respostas fisiológicas, das pessoas diante do Tijolo Esperto, e destacamos o prazer que os estímulos visuais insinuam e proporcionam, independente de seu conhecimento artístico ou cultural. A obra foi produzida para mostrar também figuras com diferentes graus de complexidade, variando o tempo e a repetição de exposição das mesmas. Percebemos que imagens simples e estímulos monótonos, sem movimento, praticamente não interessavam aos interatores. Já os estímulos complexos sempre renovados estimulavam o público a permanecer diante da obra. O estímulo moderado eram consideradas agradáveis, mas se fosse muito intenso, ocorria o desprazer, provocando o afastamento físico do objeto. A sensação de compreender melhor a imagem a cada nova apresentação levava à redução do alerta, produzindo prazer semelhante à resolução de um enigma.

\section{TIJOLO ESPERTO}

A obra de arte Tijolo Esperto é o resultado de uma pesquisa iniciada em 2008, que foi desenvolvida com a participação de alunos da graduação e da pós-graduação da Universidade de Brasília, no Laboratório de pesquisa em arte computacional, do departamento de artes visuais.

É considerado um projeto de co-autoria com Breno Guimarães Rocha (desenvolvedor do sistema hardware), Thiago Coelho Vieira (programador de software), Fábio Fonseca (artista), Lauro Gontijo (artista), Ronaldo Ribeiro (artista), e equipe do Midialab, como Ana Lemos, Amanda Priscilla M., Juliana Hilário, Lucas Almeida, Leonardo Guilherme, entre outros, que de alguma maneira colaboraram com a ideia.

O protótipo da obra foi premiado no edital Rumos Arte Cibernética em 2010, do Itaú Cultural, recebendo um prêmio de 50 mil reais para ser desenvolvido durante 1 ano, e em seguida, 2011, foi exposta na galeria do Itaú Cultural, localizada na Av. Paulista, em São Paulo. 


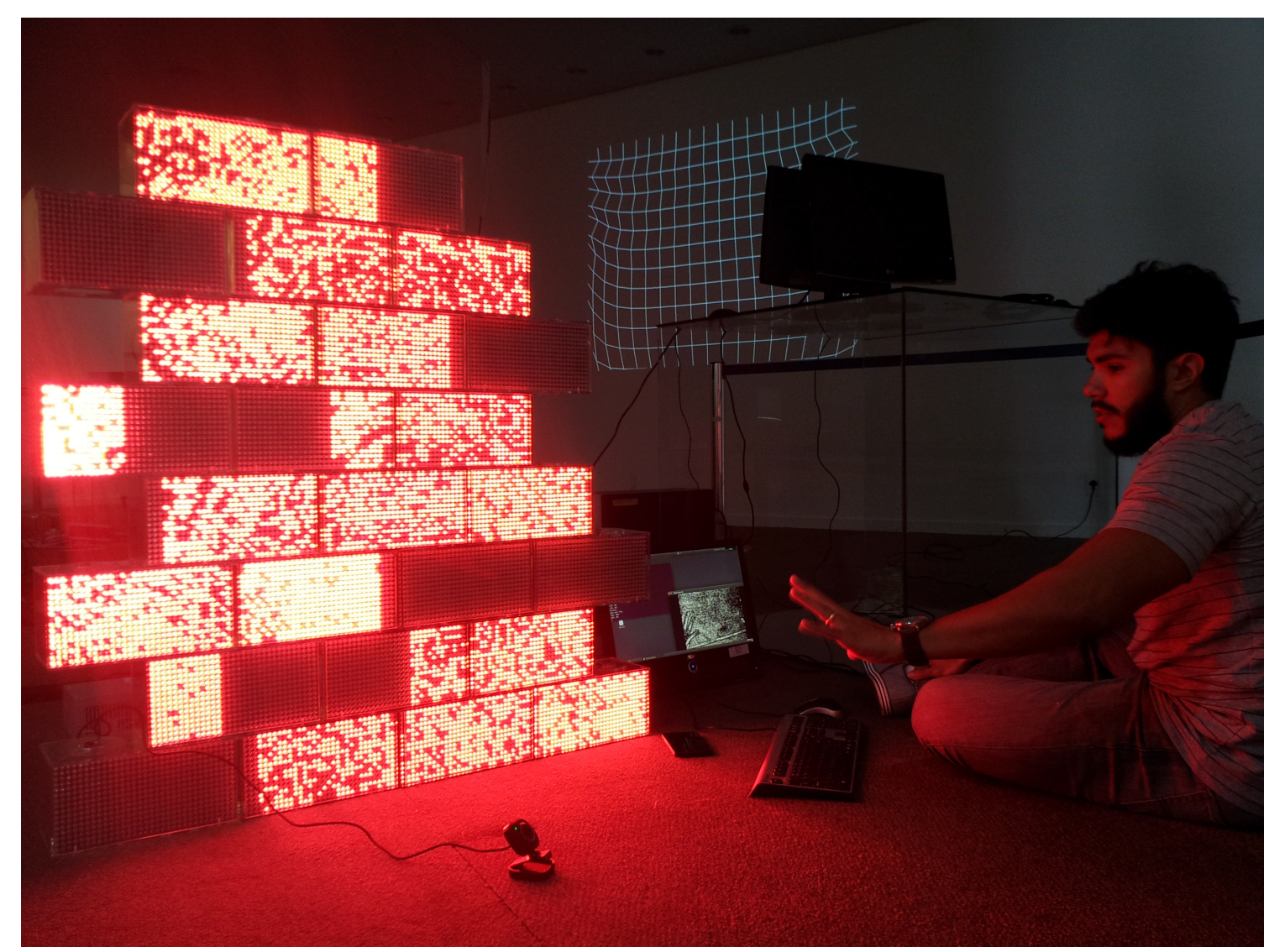

Figura 1 - Tijolo Esperto na exposição de arte computacional Museu Nacional da República, 2014

Tijolo Esperto é uma parede interativa construída a partir de tijolos translúcidos, nos quais as superfícies são cobertas internamente por uma matriz de LEDs - diodos emissores de luz, que quando energizados positivamente emitem luz visível. As imagens e animações são formadas pela disposição de um grupo de tijolos, os quais se comunicam, formando imagens maiores e mais complexas Um dos pilares da obra está na exibição do Jogo da Vida de John Conway. O Jogo da Vida é um autômato celular que consegue reproduzir uma atividade artificial, simulando aumento, redução e alteração de uma comunidade de seres vivos, gerando efeitos de imagem interessantes e imprevisíveis. O Jogo da Vida de Conway cria um universo complicado a partir de poucas regras simples Na obra Tijolo Esperto, a população inicial da comunidade do Jogo da Vida pode ser gerada de diversas formas, a partir de imagens predefinidas, de forma aleatória, e de imagens retiradas em tempo real do espaço em que a obra está montada, por meio de uma webcam. 


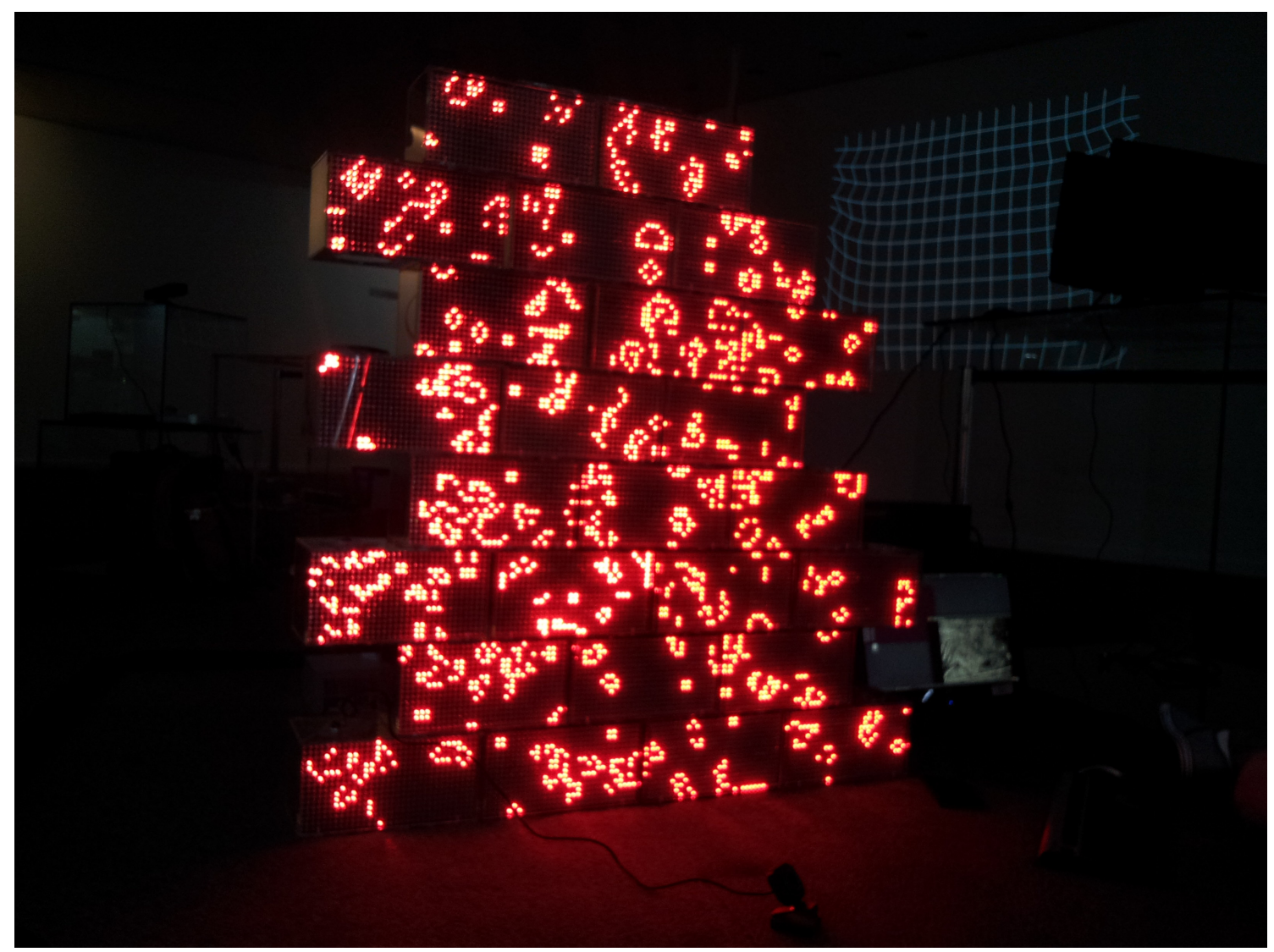

Figura 2- Tijolo Esperto na exposição de arte computacional Museu Nacional da República, 2014

A proposta concentrou-se na produção de conhecimento acerca dos processos que contribuem para o desenvolvimento de softwares e hardwares livres como linguagem e meio artísticos. A expectativa é que essa produção contribua para a criação de espaços físicos artísticos, a ser habitados ou não, oferecendo uma realidade conectada entre sistemas naturais e artificiais. O Tijolo Esperto possibilita entender as atribuições e qualificações de arquitetos, designers e artistas em projetos que exigem uma aproximação transdisciplinar, envolvendo parcerias com vários campos - em particular com as artes, as engenharias e a ciência da computação -, procurando estabelecer relações que explorem novas demandas, ferramentas e possibilidades para essas áreas É importante destacar o papel triplo desempenhado pela proposta. Além de uma instalação artística interativa, seu processo de concepção e desenvolvimento constituiu uma pesquisa em que diversas pessoas foram envolvidas e por meio da qual as discussões e os conhecimentos são agregados ao repertório prático e conceitual da equipe. Por fim, caracterizou-se também como uma plataforma aberta da qual outras pesquisas poderão se apropriar como meio para exploração de conceitos que englobam a introdução de sistemas interativos no campo da arte e da tecnologia. 


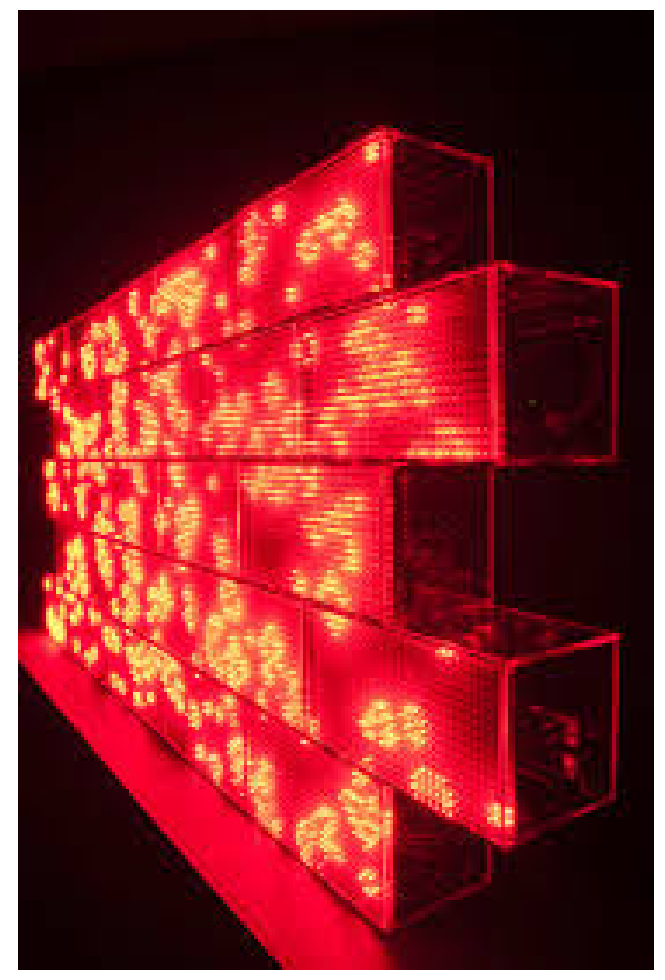

Figure 4 - Tijolo Esperto na exposição de arte cibernética Itaú Cultual, 2011

Também pode ser considerada uma pesquisa artística, cujo objetivo foi o desenvolvimento de uma parede interativa construída a partir de uma matriz luminosa de tijolos interativos. Esta funciona através de um sistema constituído por leds, Diodos Emissores de Luz, que quando energizados positivamente emitem luz visível, através da qual imagens e animações podem ser visualizadas. O projeto ilustrou a preocupação da equipe do Midialab em explorar instâncias do habitar interativo através da prática da experimentação dos meios digitais no ambiente construído.

A proposta concentrou-se na produção de conhecimento acerca dos processos interativos que contribuem para o desenvolvimento de softwares e hardwares livres como linguagem e meio artísticos. Essa produção, contribuirá para a criação de espaços físicos, artísticos, a serem habitados, oferecendo uma realidade conectada entre sistemas naturais e artificiais. O Tijolo Esperto possibilita entender as atribuições e qualificações de arquitetos, designers e artistas em projetos que exigem uma aproximação transdisciplinar, envolvendo parcerias com outros campos - em particular, com as Engenharias Mecatrônica e Ciência da Computação e as Artes - procurando estabelecer relações que explorem novas demandas e 
ferramentas para a arte e tecnologia.

O tópico principal do nosso projeto foi trabalhar com o desenvolvimento de objetos inteligentes que possam ser programados de acordo com um algoritmo específico, que permite a interação. Nosso objetivo consiste na concepção de um tijolo translúcido, no qual as superfícies serão cobertas internamente por uma matriz de leds. Cada tijolo se comunica com os demais tijolos dispostos, de modo a formar uma parede sistêmica capaz de exibir imagens maiores e mais complexas, por meio da intercomunicação dos vários tijolos e interação com o público.

Cada led se comporta como um pixel de luz de baixa resolução em uma matriz composta por 240 leds, que são controlados individualmente, para possibilitar a produção de imagens e animações luminosas em movimento e em tempo real.

As informações básicas são discutidas com outros pesquisadores interessados em fazer parte do processo. É importante destacar o papel triplo desempenhado pela proposta. Além de uma instalação artística interativa, seu processo de concepção e desenvolvimento constitui uma pesquisa em que diversas pessoas são envolvidas e através da qual as discussões e conhecimentos são agregados aos repertórios prático e conceitual do grupo. Por fim, caracteriza-se também como uma plataforma aberta que outras pesquisas poderão se apropriar como meio para exploração de conceitos que englobam a introdução de sistemas interativos na arte e tecnologia.

\section{MOTIVAÇÃO, EMOÇÃO E RAZÃO EM HARMONIA}

$\mathrm{Na}$ busca de conhecimento, emoção e motivação, verifica-se a forte relação entre a arte e a ciência. Enquanto a ciência busca a verdade universal, arte procura provocar o equilíbrio entre a emoção e a razão? A hipótese que se apresenta, em particular na neuroestética, é que as funções cognitivas; consciência e atividade artística estão associadas com o maior desenvolvimento da organização cerebral, que durante a nossa evolução, se manifestou principalmente com a expansão do córtex cerebral, em estreita relação com o sistema límbico, que é a unidade responsável pelas emoções. 
Platão, como se sabe, distinguia a ideia de uma coisa, quando inteligível, do modelo da coisa que o artesão tinha no pensamento, da coisa executada, por exemplo, por um marceneiro e dela pintada numa parede. As equivalências na neuroestética destas distinções são: o conceito - primeira imagem, o conceito - objeto fabricado e finalmente a pintura na parede ou numa tela, como representação do conceito. Encontramos aqui a definição de arte como mimese traduzida como representação/imitação. A definição de arte em geral como imitação da natureza foi legitimada nos século 16 e 17, tendo Aristóteles como autoridade no assunto. Ainda hoje, muitos intérpretes entendem isso como a marca mais evidente da influência de Aristóteles sobre a constituição da teoria da arte. Para Aristóteles, de um modo geral, a arte (tekhnê) ou bem executa aquilo que a natureza é impotente em realizar ou a imita. As coisas artificiais são produzidas para qualquer finalidade, assim como as coisas da natureza, pois nas coisas artificiais e naturais as consequências e os antecedentes possuem entre elas a mesma relação. A mimesis poética a que se refere Aristóteles, não diz respeito a natureza mas sim à história; ela é uma imitação das ações humanas (mimesis praxeos). Ao atribuirmos a Aristóteles a idéia de que a arte, o sentido artístico, é uma imitação da natureza, implica que estamos fazendo uma transferência de significado dos termos do plano da física para o plano da poética, da arte no sentido de tekhnê para a arte no sentido de poiesis (CARTERON, 1973).

A tradução da tekhnê por ars, e depois por "arte", ocorreu em função da língua grega não possuir uma palavra para o que chamamos de arte, no sentido de belas artes, ou seja, confunde no mesmo termo dois significados que nas línguas europeias, desde o Renascimento, têm procurado distinguir, a saber: a arte do artista, o pintor ou escultor, e a arte do artesão, que é o trabalhador que incorpora a distinção estabelecida a partir da Idade Média entre as artes liberais e ofícios. Seu pensamento mostra que a atividade artística é uma tendência natural fonte de prazer e instrumento de conhecimento, posto que é mimese. A mimese não nos deixa enganar. Fazemos a diferença do que é real e sua imagem. A arte não é só agradável, mas é útil para o indivíduo. A arte não é somente representação, ela se integra na natureza. Hegel dizia que a arte não é somente uma imitação da natureza, pois ela realiza um acordo entre o sensível e o inteligível. O belo é a manifestação sensível da idéia, do espírito (cérebro?).

Na neurobiologia, segundo Jean-Pierre Changeux (2010), a mimese aporta questões relacionadas à fisiologia, ou seja, à percepção, à psicologia e à sociedade. Por exemplo, a percepção de relações na imagem pode ser comparada àquelas dos ritmos endógenos e 
harmonizados sobre o modelo da música? Ou ainda, mais especificamente como o inteligível interage com o sensível no mundo interior do artista no espaço estético consciente? Se o enfoque são os códigos, discutindo a idéia de que o artista se expressa pela arte, seu cérebro, neste caso, é o reflexo da sociedade, como sugere Max, ou a sociedade reflete o cérebro do ser humano?

Considerando as pesquisas e trabalhos realizados nos últimos 30 anos, que a obra de arte tem traços em comum com o "modelo científico": ela é ao mesmo tempo serendipite, ocorre por acidente, reducionista e reveladora. Paradoxalmente, diz Changeaux, para mostrar a verdade muitas vezes foi necessário enganar. Por exemplo, a ilusão do cavalo a galope com as quatro patas no ar pintado por Derby d’Épsom de Géricault ou ainda a posição impossível do homem que anda do escultor Rodin, levou-o a escrever que é o artista que diz a verdade e que é a fotografia que mente, pois na realidade o tempo não pode ser parado.

\section{CONSIDERAÇÕES FINAIS}

As reflexões aqui apresentadas estão contidas num livro intitulado Arte Computacional, ainda não publicado. E, portanto, tem como fonte operacional a arte computacional que, por sua vez, mesmo ocasionada por conceitos que surjam a partir de ideias estéticas, é hoje minimamente escrita, com base na informática. A escritura informatizada que defino aqui como n-dimensional, contém dois eixos interessantes, que destaco dentre as possíveis dimensões estéticas. Eles conduzem trajetórias da geração de artistas dos anos 1980, ou seja, num eixo encontra-se a construção invisível elaborada de formalismos logísticos integrados numa arquitetura de códigos, e num segundo eixo uma poética de formas sociais de expressão fundamentada na memória da tradição da escrita, que é a da computação, como herança de uma tradição, traduzida nas operações do código binário, está em evolução, no sentido darwinista. A tradução torna legível e interpretável a memória social de camadas de escrituras do conhecimento. A arte computacional procura trazer, a partir da tradição, questões de ordem científica para o contexto da arte e da estética hoje. 


\section{REFERÊNCIAS BIBLIOGRÁFICAS}

BERLYNE, Daniel. http://konecni.ucsd.edu/pdf/26.pdf. Acessado em 12-01-2012.

Novelty, complexity, and hedonic value Perception \& Psychophysics, 8 (5), 279-286 DOI: 10.3758/BF03212593, 1970.

CARTERON, H. Aristote Physique (I-VIII). Paris: les Belles Lettres, 1973.

CHANGEUX, Jean-Pierre. Sobre lo verdadero, lo bello y el bien. Un nuevo enfoque neuronal. Buenos Aires: Katz Editores, 2010.

. Raison et Plaïsir. Paris: Odile Jacob, 2002.

DELEUZE, Gilles. Empirismo e Subjetividade: ensaio sobre a natureza humana segundo Hume. Tradução de Luiz B. L. Orlandi. São Paulo: Ed.34, 2001.

Cinema II: A Imagem-tempo. São Paulo: Brasiliense, 2007.

Pos-Scriptum sobre a Sociedade de Controle, in Conversacões. Editora

34. Rio de Janeiro.

VENTURELLI, Suzete. Arte Computacional. (Livro ainda não publicado). 